\title{
Genetic Diseases of the Kidney
}

\author{
John Foreman ${ }^{*}$
}

Division of Pediatric Nephrology, Duke University Medical Center, Durham, NC, USA

\begin{abstract}
The number of genes associated with renal disease is increasing every day and this has led to a clearer understanding of the pathophysiology of renal disease in many disorders. It is also appreciated now that a genetic mutation(s) underlie many renal syndromes. Genetic testing may also offer the possibility to diagnose some renal diseases without the need for a renal biopsy. It also allows the prenatal diagnosis of certain renal diseases in at risk fetuses or identification of potential renal disease before it has become manifest. Finally, identification of a specific gene mutation holds the possibility of correction though gene therapy in the future. It is increasingly clear that many renal disorders in pediatrics are a consequence of genetic mutations. In the future, genetic testing will become as easy and as common as ordering a serum creatinine today.
\end{abstract}

Keywords: Basement membrane disorders, cystic kidney disease, genetics, genetic renal disorders, nephrotic syndrome, mutations, renal tubular acidosis.

\section{INTRODUCTION}

The number of genes associated with renal disease is increasing every day and this has led to a clearer understanding of the pathophysiology of renal disease in many disorders. It is also appreciated now that a genetic mutation(s) underlie many renal syndromes. Genetic testing also offers the possibility to diagnose some renal diseases without the need for a renal biopsy. It also allows the prenatal diagnosis of certain renal diseases in at risk fetuses or identification of potential renal disease before it has become manifest. Finally, identification of a specific gene mutation holds the possibility of correction though gene therapy, although gene therapy remains only a promise at this point in time.

The first step in identifying a genetic renal disorder is to consider it. A gene mutation should be thought of if another family member is affected, if there are other malformations in addition to the renal disease, or if the clinical course is different from that of the typical patient with this disorder.

However, there are a number of problems associated with genetic testing. First, the identification of a gene mutation for many renal diseases remains a research procedure that requires informed consent and often this information cannot be used for making clinical decisions. Further, most genetic renal disorders are caused by a number of mutations in a given gene and can be caused by a mutation in more than one gene. This makes the identification of the precise mutation in the right gene in a given patient difficult. Commercially available genetic testing laboratories often only identify the common mutations, thus missing some patients. Not all insurance carriers will pay for genetic

*Address correspondence to this author at the Division of Pediatric Nephrology, Duke University Medical Center, 2301 Erwin Rd \# 7407, Durham, NC 27705, USA; Tel: 919-684-4246;

E-mail: john.foreman@duke.edu testing. Finally, genetic testing itself carries the risk of labeling someone as a carrier or a potential victim of a disease that may have long-term implications.

\section{GENETIC DISORDERS AFFECTING THE GLOMERULUS}

\subsection{Podocyte - Nephrotic Syndrome (Table 1, Fig. 1)}

The majority of infants, especially in the first 3 months of life, with nephrotic syndrome have a mutation in both copies of one of several different genes [1]. The first to be described was congenital nephrotic syndrome of the Finnish type that has an incidence in Finland of 1 in 10,000 newborns [2]. It is much rarer in other countries. It is caused by a defect in the gene, NPHS1, that codes for the protein, nephrin, found in the slit diaphragm. Infants with Finnish congenital nephrotic syndrome have massive proteinuria that begins in utero and are born prematurely with very large placentas. Edema is either present at birth or appears shortly afterwards and is difficult to manage. There is no specific therapy except nephrectomy and ultimately renal transplantation.

Other causes of congenital nephrotic syndrome include mutations in NPHS2, which codes for podosin [3], PLCE1 [4], which codes for PLCE1, and WT1 [5] which codes for Wilms tumor suppressor gene. Podosin is important in the formation of the slit diaphragm and intracellular signaling. PLCE1 or phospholipase $\mathrm{C}$ epsilon generates diacylgycerol and inositol 1,4,5-triphosphate that is important for intracellular signaling in the podocyte. A mutation in both copies of either gene leads to the nephrotic syndrome and rapid progression to end-stage renal disease (ESRD). Infants with genetic mutation mediated nephrotic syndrome are resistant to steroid therapy, although a few infants with a PLCE1 mutation have responded to cyclosporine [5].

Denys-Drash syndrome [5], due to a mutation in WT1, presents in infancy with nephrotic syndrome and in males 
Table 1. Genetic disorders of the podocyte.

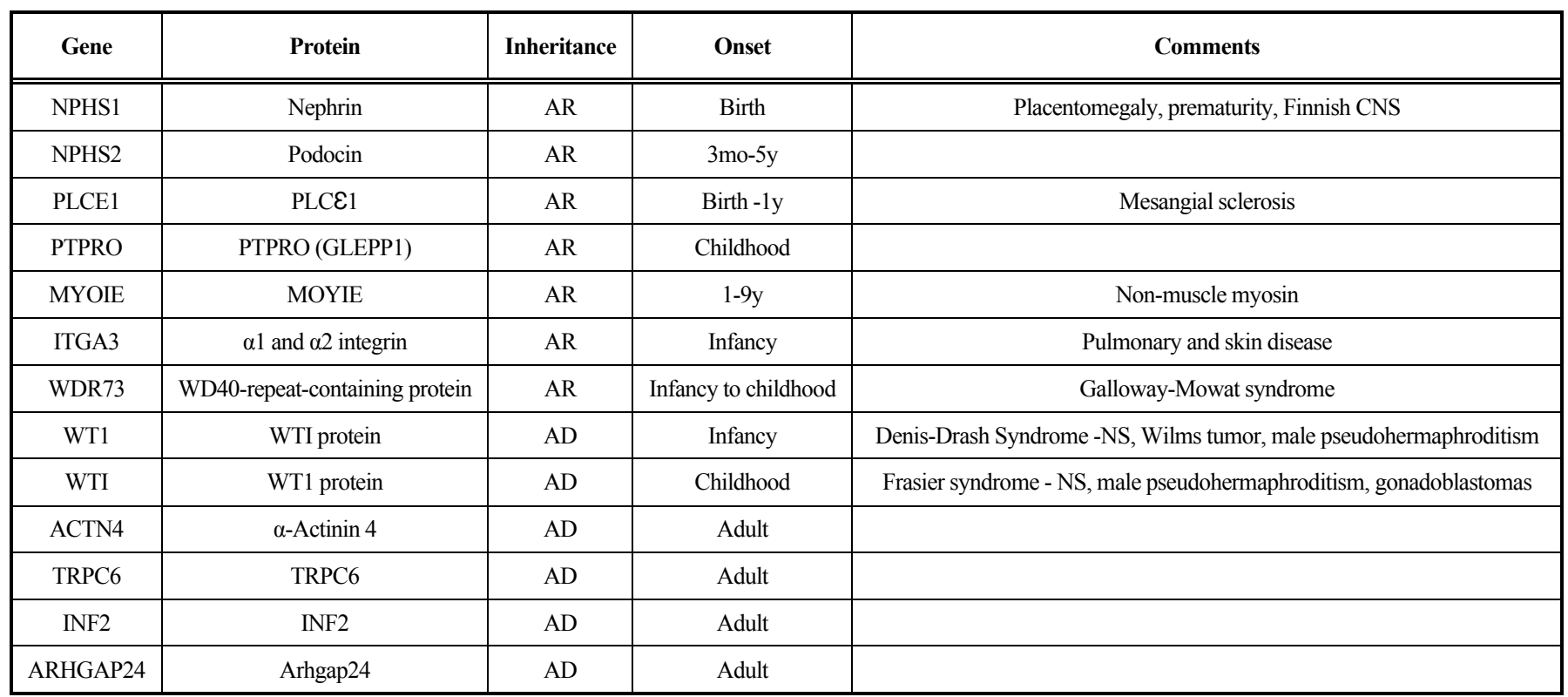

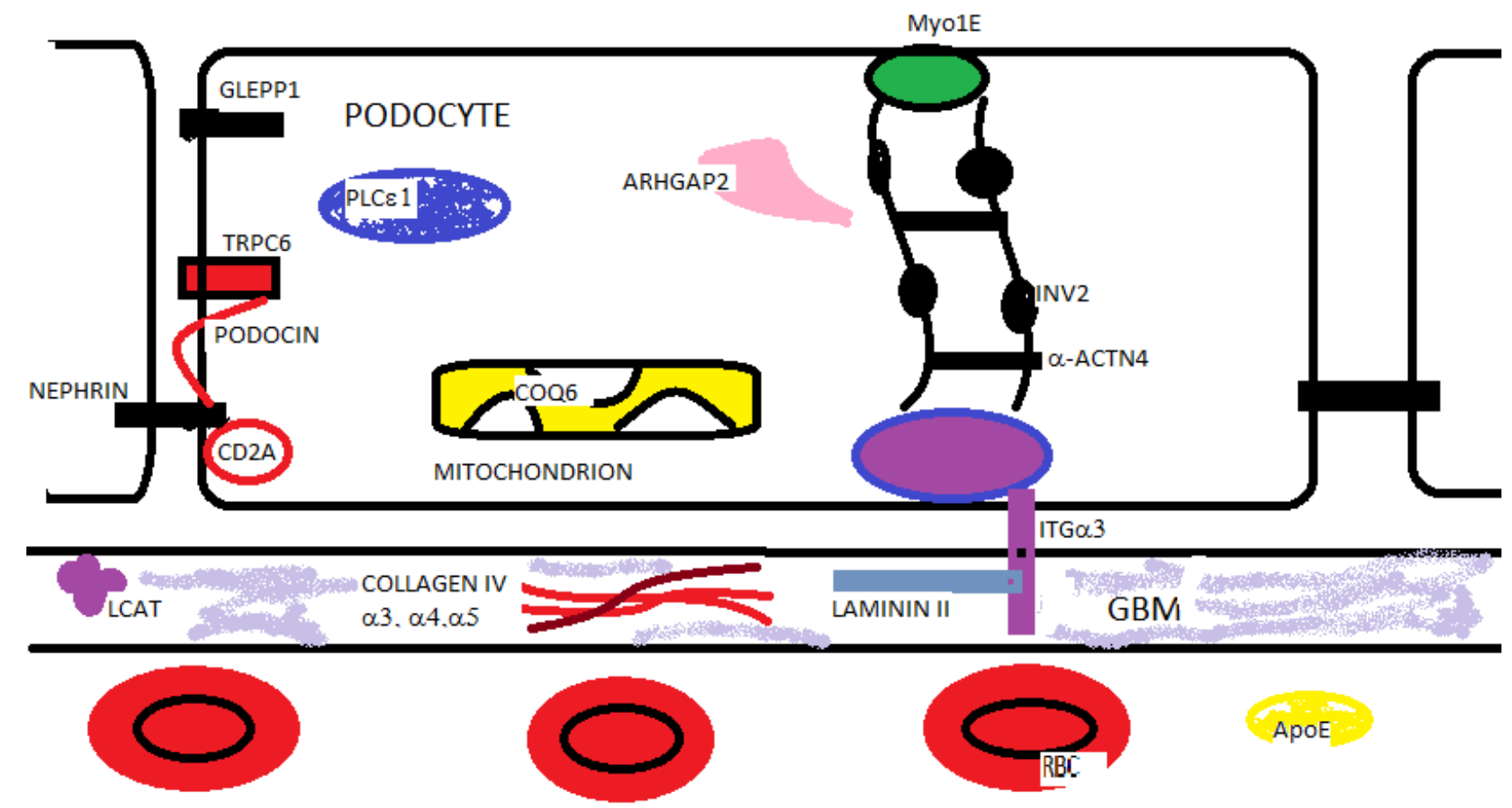

Fig. (1). Glomerular Proteins in Hereditary Renal Disease. Nephrin, podosin, PLCE1, Myo1E, Arhgap2, GLEPP1 (PTPRO) are podocyte proteins associated with autosomal recessive nephrotic syndrome. TRPC6, INF2, and $\alpha$-ACTN4 are proteins mutated in autosomal dominant nephrotic syndrome. Mutations in the mitochondrial enzyme co-enzyme Q6 (COQ6) and the $\alpha-3$ subunit (ITG $\alpha 3$ ) of the transmembrane integrin are also associated with nephrotic syndrome. Mutations in the glomerular basement membrane (GBM) proteins - collagen IV $\alpha 3,4,5$ chains and laminin II cause renal disease. Lecithin-cholesterol acyltransferase deficiency leads to lipid deposits in the GBM and renal disease. Laminated apolipoprotein (APOE) deposits are found in the capillary in lipoprotein glomerulopathy.

with ambiguous to female genitalia. These patients have diffuse mesangial glomerulosclerosis on kidney biopsy and they also develop Wilms tumor. The nephrotic syndrome is refractory to immunosuppressive therapy and patients with it usually progress to renal failure by age 3 years. GallowayMowat syndrome is a rare autosomal recessive condition that is characterized by microcephaly, neurologic impairment and nephrotic syndrome [6]. It is probably genetically heterogeneous, but a mutation in $W D R 73$ was described in a single family. WDR73 codes for a WD40-repeat-containing protein of unknown function, but appear to play a role in maintenance of cell architecture and survival. 
While the majority of pediatric patients with nephrotic syndrome respond to steroids, approximately $20-40 \%$ do not. Of those that do not, it is estimated that as high as a third have a genetic disorder causing the nephrotic syndrome [7]. The most common cause of this is a mutation in NPHS2 [8, 9]. A few children with steroid-resistant nephrotic syndrome have a mutation in PTPRO or MYOIE [10]. The pathogenesis of nephrotic syndrome in these disorders is unclear, but both cause foot process effacement, focal segmental glomerulosclerosis [FSGS], and rapid progression to ESRD. Frasier syndrome [11] is caused by a different mutation in WTI from that which causes the Denys-Drash syndrome and causes male pseudohermaphroditism and nephrotic syndrome in late childhood with FSGS [12]. Affected individuals can also develop gonadoblastomas.

In contrast to genetic causes of nephrotic syndrome in infancy and childhood that are mainly inherited as autosomal recessive traits, genetic causes of nephrotic syndrome that present in adolescence and adulthood are usually inherited as an autosomal dominant trait and with the pathological changes typical of FSGS. The first to be described was a mutation in the gene coding for $\alpha$-actinin- 4 protein [13]. Alpha-actinin-4 plays an important role in maintaining the cytoskeleton of the podocyte. A mutation in the gene coding for the transient receptor potential cation channel 6 [TRPC6] protein [14] also causes autosomal dominant nephrotic syndrome. Abnormalities in channel activity leads to increased intracellular calcium in the podocyte that interferes with cell function and increased apoptosis of the podocyte. Mutations in the formin gene, INF2, cause autosomal dominant FSGS [15]. INF2 protein is involved in the regulation of acting and maintenance of the cytoskeleton of the podocyte. Similarly, a mutation in the gene ARGHGAP24 coding for the Rac1 regulatory protein, Arhgap24, causes dysregulation of the podocyte actin cytoskeleton and autosomal dominant FSGS [16].

\subsection{Basement Membrane Disorders (Table 2)}

Hereditary nephritis or Alport syndrome is caused by a mutation in the genes coding for the alpha-3,4, or 5 chains of type IV collagen [17] and causes progressive glomerular disease often associated with neural deafness and eye abnormalities. It is the most common basement membrane disorder causing kidney disease with an incidence of $1 / 5000$ live births and accounts for $2 \%$ of the new cases of ESRD [18]. The initial manifestation is microscopic hematuria that occurs early in life with progressive renal disease that leads to ESRD by the second to third decade of life. The most common form of Alport syndrome is a mutation in COL4A5 gene located on the $\mathrm{X}$ chromosome coding for the alpha5(IV] chain and accounts for about $80 \%$ of Alport patients. Males are severely affected while most females have only hematuria, but some female carriers do develop renal failure. Approximately $15 \%$ of Alport patients have an autosomal recessive inheritance pattern and the mutation is in either the COL4A3 or COL4A4 genes that code for the alpha-3 and alpha-4 chains of type IV collagen, respectively [18].

Thin basement membrane disease is a relatively common familial disorder and is characterized by a glomerular basement membrane that is thinner than normal [19]. Patients affected by this disorder have isolated hematuria that is inherited in an autosomal dominant pattern. The defect is a mutation in one of the COL $4 A 3$ or COL $4 A 4$ genes [17-19]. These are the same genes associated with autosomal recessive Alport syndrome. Patient with thin basement disease rarely have significant proteinuria or progress to renal failure. They also don't develop hearing loss or eye changes.

Nail-patella syndrome is a rare autosomal dominant condition characterized by hypoplastic or absent patellae, dysplastic nails and elbows, iliac horns, and proteinuria [20, 21]. Nail-patella syndrome is caused by a mutation in the transcription factor $L M X 1 B$. Proteinuria occurs in about half of affected individuals and a minority of these patients progress to renal failure. The glomerular basement membrane has a characteristic "moth-eaten" appearance from multiple irregular lucencies.

Pierson syndrome is a rare autosomal recessive disorder caused by a mutation in $L A M B 2$ which codes for laminin $\beta 2$ [22]. Renal disease usually starts early in life with nephrotic syndrome and progresses to ESRD within the first year of life. They also have buphthalmos, microcoria, hypotonia and profound psychomotor retardation. They have diffuse basement membrane abnormalities with mesangial sclerosis.

Mutations of ITGA3, which encodes for the transmembrane integrin $\alpha_{3}$ subunit, can cause congenital nephrotic syndrome. Infants with this mutation had marked irregularities of the

Table 2. Genetic disorders of the glomerular basement membrane disorders.

\begin{tabular}{|c|c|c|c|c|}
\hline Gene & Protein & Inheritance & Onset & Comments \\
\hline$\alpha-5$ chain & $\alpha-5$ chain & X-linked & $\begin{array}{l}\text { Early } \\
\text { childhood }\end{array}$ & Alport syndrome - ESRD at 2-4 decade, Deafness \\
\hline $\begin{array}{l}\text { Heterozygous } \alpha-3 \text { or } \alpha-4 \\
\text { mutation }\end{array}$ & $\alpha-3$ or $\alpha-4$ chain & $\mathrm{AD}$ & $\begin{array}{c}\text { Early } \\
\text { childhood }\end{array}$ & Thine basement membrane disease -Familial hematuria \\
\hline $\begin{array}{l}\text { Homozygous } \alpha-3 \text { or } \alpha-4 \\
\text { mutation }\end{array}$ & $\alpha-3$ or $\alpha-4$ & $\mathrm{AR}$ & $\begin{array}{c}\text { Early } \\
\text { childhood }\end{array}$ & Alport syndrome - ESRD at adolescence, deafness \\
\hline LMX1B & LMX1B & $\mathrm{AD}$ & Variable & $\begin{array}{c}\text { Nail-Patella syndrome - Dysplastic nails and patellae, variable degree } \\
\text { of renal involvement }\end{array}$ \\
\hline ITGA3 & $\begin{array}{l}\text { Integrin } \alpha_{3} \\
\text { subunit }\end{array}$ & AR & Infancy & Kidney disease, lung disease, epidermolysis bullosa \\
\hline
\end{tabular}


Table 3. Lipid and mitochondrial abnormalities causing NS.

\begin{tabular}{|c|c|c|c|c|}
\hline Gene & Protein & Inheritance & Onset & Comments \\
\hline \hline ApoE & Apolipoprotein E & AD & Adulthood & Lipid glomerulopathy with lipid thrombi, Asian descent \\
\hline LCAT & Lecithin:cholesterol acyltransferase & AR & Adulthood & Corneal opacities, hepatosplenomegaly, anemia, CKD \\
\hline CoQ6 & Coenzyme Q6 & AR & Infancy & NS, sensorineural deafness, ESRD \\
\hline
\end{tabular}

basement membrane in the kidney, lung, and epidermis with interstitial lung disease and epidermolysis bullosa [23].

\subsection{Lipid Abnormalities Causing Nephrotic Syndrome (Table 3)}

Liproprotein glomerulopathy presents in adulthood with proteinuria and rapid progression to ESRD. It occurs mainly in individuals of Asian ethnicity. There is extensive deposition of laminated lipid thrombi in glomerular capillaries and affected individuals have type III hyperlipidemia [24]. Lecithin: cholesteraol acyltransferase deficiency is an autosomal recessive abnormality characterized by lipid abnormalities, corneal opacities, nephrotic syndrome and progressive renal disease. The basement membrane has a "vacuolized" appearance from lipid droplets [25].

\subsection{Glomerular Mitochondrial Disorders (Table 3)}

Mutations of the mitochondrial enzyme CoQ6 cause nephrotic syndrome and sensorineural deafness [26]. CoQ6 is necessary for the biosynthesis of CoQ10 which is essential for proper functioning of the electron transport chain. Nephrotic syndrome associated with CoQ6 mutations is inherited in an autosomal recessive pattern and all children progressed to ESRD by late childhood.

\section{GENETIC DISORDERS AFFECTING THE PROXIMAL TUBULE (FIG. 2, TABLE 4)}

Hereditary renal glucosuria is a rare disorder occurring in 1 in 20,000 individuals and is marked by glucosuria when the blood glucose in the normal range [27]. It is caused by a mutation in the gene, SLC5A2, that codes for the SGLT2 glucose transporter [28]. It is inherited as a co-dominant trait, thus individuals with a single gene mutation have glucosuria. Affected individuals are otherwise normal.

Cystinuria is characterized by the excessive excretion of cysteine and the dibasic amino acids ornithine, lysine and arginine [29, 30]. Cystine is relatively insoluble when its concentration exceeds $250 \mathrm{mg} / \mathrm{L}$ and affected individuals have recurrent stones disease. It occurs with a incidence of $1 / 20,000$ and is caused by a mutation in both $S L C 3 A 1$ genes, which codes for the protein rBAT, or both SLC7A9 genes, which codes for the protein $b^{0,+}$ AT1 [30]. These two proteins form a heterodimer responsible for cystine and dibasic amino acid transport across the proximal tubule brushborder membrane. Patients that are compound heterozygotes also have cystinuria.

Hereditary hypophosphatemic rickets with hypercalciuria is a rare, autosomal recessive disorder cause of hypophosphatemia [31]. It is characterized by mutations in the $S L C 34 A 3$ gene which codes for the $\mathrm{Na}^{-} \mathrm{PO}_{4}$ transporter in the proximal tubule brushborder. The hypophosphatemia causes excessive production of 1,25-vitamin D and hypercalciuria. This disorder is distinct from the more common X-linked hypophosphatemic rickets that is caused by abnormalities in PEX that regulates fibroblast growth factor 23 and phosphate reabsorption [32].

Inherited proximal renal tubular acidosis [RTA] can be caused by a mutation in both $C A 2$ genes coding for carbonic anhydrase II [33]. Patients with this disorder also have distal RTA and osteopetrosis. Proximal RTA can also be caused by

Table 4. Proximal tubule genetic disorders.

\begin{tabular}{|c|c|c|c|l|}
\hline Gene & Protein & Inheritance & Onset & \multicolumn{1}{|c|}{ Comments } \\
\hline \hline SLC5A2 & SGLT2 & AD & Birth & Benign glucosuria \\
\hline SLC3A1 & rBAT & AR & Infancy to adulthood & Cystinuria, dibasic aminoaciduria, renal stones \\
\hline SLC7A9 & B $^{0,+}$ AT1 & AR & Infancy to adulthood & Cystinuria, dibasic aminoaciduria, renal stones \\
\hline SLC34A3 & Na-PO4 transporter & AR & Infancy & Hereditary hypophosphatemic rickets \\
\hline CAII & Carbonic anhydrase II & AR & Infancy & FTT, proximal and distal RTA, osteopetrosis \\
\hline SLC4A4 & NBC1 & AR & Infancy & FTT, proximal RTA, developmental delay, eye disease \\
\hline CTNS & Cystinosin & AR & Infancy & Cystinosis -Fanconi syndrome, FTT, hypothyroidism, eye disease, ESRD \\
\hline CLCN5 & CLC-5 chloride channel & AR & Infancy & Dent disease - kidney stones, nephrocalcinosis, Fanconi syndrome, ESRD \\
\hline OCRL & INPP5F & X-Linked & Infancy & Dent disease \\
\hline OCRL & INPP5F & X-Linked & Infancy & Lowe syndrome - developmental delay, ocular disease, Fanconi syndrome, ESRD \\
\hline SLC22A12 & URAT1 & AR & Infancy & Hereditary hypouricemia \\
\hline
\end{tabular}




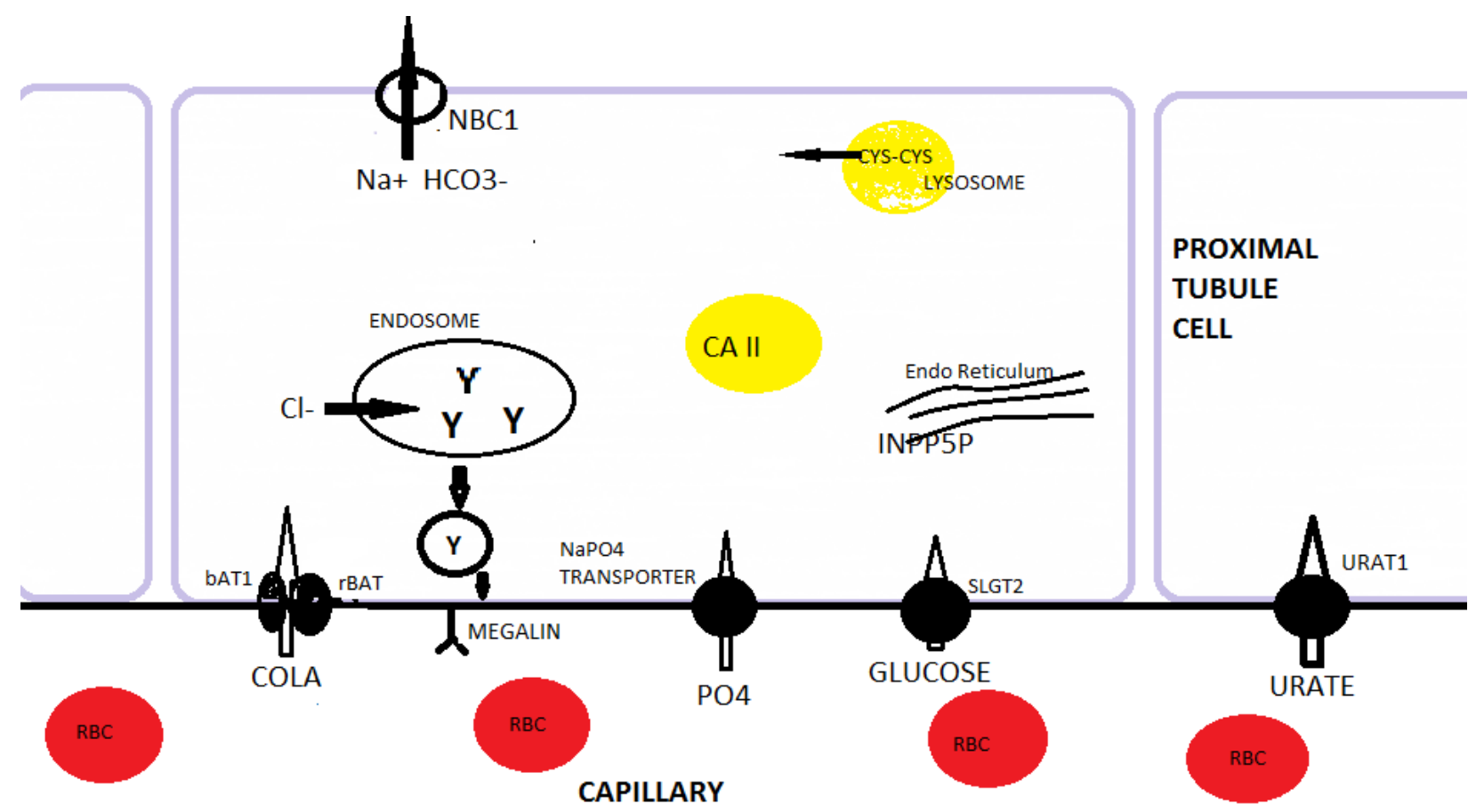

Fig. (2). Hereditary Disorders of the Proximal Tubule. Hereditary renal glucosuria is caused a mutated sodium-glucose transporter SLGT2. A mutated bAT1 or BAT protein, which make up the luminal cystine and dibasic aminoacid transporter leads to cystinuria. Proximal RTA can be caused by a mutated carbonic anhydrase II (CA2) or the basolateral membrane sodium-bicarbonate transporter (NBC1). Hereditary hypophosphatemic rickets is caused by a mutated sodium-phosphate transporter in the luminal membrane. Hereditary hypouricemia is caused by a mutated urate transporter URAT1. A mutated cystinosin in the lysosomal membrane leads to cystine storage and Fanconi syndrome (FS). Mutated phosphotylinositol-4,5-biphosphate 5-phosphatase (INPP5P) in the Golgi apparatus leads to Lowe syndrome and FS. FS is also caused by a mutation in the CLC- 5 chloride channel in the endosome leading to impaired recycling of megalin.

a mutation in both $S L C 4 A 4$ genes, which encodes for NBC1 [34]. NBC1 transports both sodium and bicarbonate across the basolateral membrane. Affected children also have psychomotor retardation and ocular abnormalities.

Fanconi syndrome is a disorder characterized by a global dysfunction of the proximal tubule, leading to hypokalemia, hypophosphatemia, acidosis, glucosuria and aminoaciduria. Many inherited metabolic diseases can cause transient Fanconi syndrome, except for cystinosis [35], Lowe syndrome [36, 37] and Dent disease [38]. Cystinosis is another rare autosomal recessive disease caused by a mutation in the CTNS gene, coding for cystinosin [39]. Cystinosin mediates the transport of cystine from the lysosome to the cytoplasm and affected individuals have excessive levels of cysteine in virtually all cells of the body [40]. Infant with cystinosis soon develop the Fanconi syndrome and later progressive renal dysfunction. With advent of cysteamine and renal transplantation to treat patients with cystinosis, numerous other organ dysfunctions have become evident including, hypothyroidism, diabetes mellitus, cardiovascular, ocular, and neuromuscular disorders [41].

Dent disease is an X-linked recessive disorder characterized by low-molecular-weight proteinuria, hypercalciuria, phosphaturia, aminoaciduria, glucosuria, nephrolithiasis and nephrocalcinosis [35, 38]. Renal failure is common and may occur by late childhood. The disorder is caused by either a mutation in the CLCN5 gene [42] which codes for the CLC-5 chloride channel or in the $O C R L$ gene [43] which codes for phosphotylinositol-4,5-biphosphate 5-phosphatase [INPP5P].
CLC-5 chloride channel activity is important for recycling megalin to the brushborder membrane [36]. Megalin plays an important role in solute reabsorption in the proximal tubule. INPP5P is involved in actin polymerization in the Golgi apparatus and defective functioning of this enzyme leads to either Lowe syndrome or Dent disease.

Lowe syndrome is another X-linked disorder causing Fanconi syndrome along with cataracts and other eye abnormalities and mental retardation [36-38]. It is caused by a mutation in the $O C R L$ gene [44]. Lowe syndrome patients typically develop ESRD by the third to fourth decade of life.

Hereditary renal hypouricemia is a rare autosomal recessive disorder characterized by hypouricemia and increased uric acid clearance [45]. It is caused by a mutation in both SLC22A12 genes which code for the brushborder membrane protein URAT1. Most individuals with renal hypouricemia are asymptomatic, although a few affected individuals have had exercise-induced acute kidney injury.

\section{ASCENDING LIMB DISORDERS (FIG. 3, TABLE 5)}

The most common ascending limb disorder is Bartter syndrome which is an autosomal recessive disease caused by a number of genetic mutations [46]. Bartter syndrome is characterized by hypochloremia, hypokalemia, metabolic alkalosis, and hypercalciuria. The underlying disorder is incomplete absorption of sodium, chloride, calcium and to some extent potassium. It can cause a mutation in the genes coding for the four proteins involved in sodium chloride 
reabsorption: $\mathrm{Na}-\mathrm{K}-2 \mathrm{Cl}$ cotransporter [Type 1] [47], renal potassium channel [Type 2] [48], renal chloride channel, $\mathrm{ClC}-\mathrm{Kb}$ [Type 3] [49], and Barttin or mutation in both chloride channels, ClC-Ka and CIC-Kb [Type 4] [50]. All are present early in life and types 1,2 , and 4 often in infancy. Type 4 is also associated with deafness. Defective chloride reabsorption impairs paracellular calcium reabsorption and leads to hypercalciuria. A gain of function mutation in the calcium ion-sensing receptor can cause a Bartter like syndrome [Type 5] since this receptor inhibits sodium chloride reabsorption when it is activated. It is inherited as an autosomal dominant trait which is also associated with hypocalcemia [51].

Familial hypomagnesemia with hypercalciuria and nephrocalcinosis is a rare autosomal recessive disorder caused by a mutation in either CLDN-16 [52] or CLDN-19 [53] genes which code for claudin 16 and 19. Affected individuals have polyuria, hypermagnesuria, hypercalciuria, tetany, recurrent nephrolithiasis and progressive loss of renal function from the nephrocalcinosis. The urinary loss of magnesium leads to hypomagnesemia, hypocalcemia and tetany. Mutations in claudin 19 also cause ocular abnormalities.

Familial juvenile hyperuricemia is a rare autosomal dominant disorder characterized by hyperuricemia from defective uric acid excretion, gout and progressive renal failure. Medullary cystic disease type 2 is probably the same disease. Most of the patients with these disorders have a mutation in the $U M O D$ gene which codes for uromodulin [Tamm-Horsfall] protein $[54,55]$.

\section{DISTAL CONVOLUTED TUBULE (FIG. 4, TABLE 6)}

Gitelman syndrome is an autosomal recessive disorder characterized by hypomagnesemia, hypokalemia, metabolic alkalosis, and tetany $[56,57]$. It is caused by a mutation in the SLC12A3 gene that codes for the sodium-chloride symporter or the thiazide-sensitive $\mathrm{Na}^{+}-\mathrm{Cl}^{-}$cotransporter [NCCT] [58]. Affected individuals usually present in late

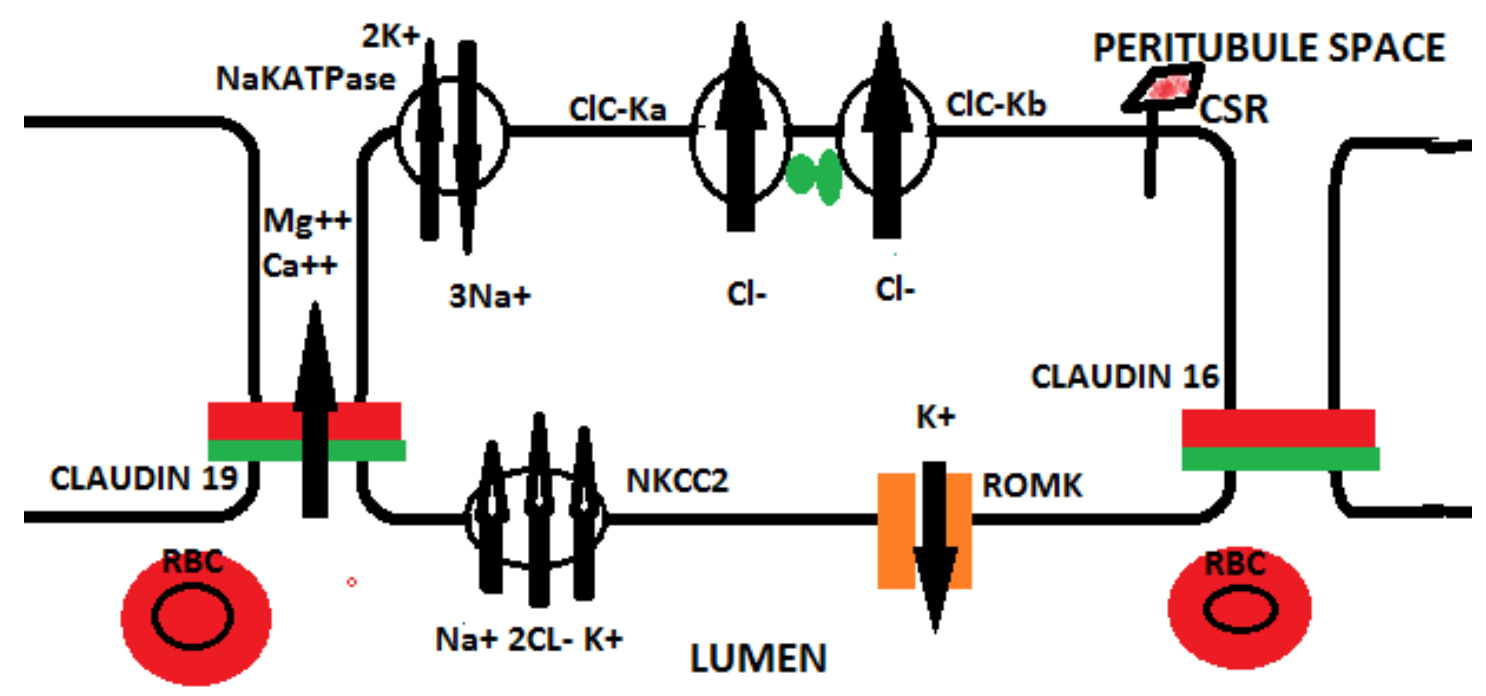

Fig. (3). Hereditary Disorders of the Thick Ascending Limb Cell. The major hereditary disorder of the ascending limb of the Loop of Henle is Bartter syndrome which can be caused by a number of mutated proteins. An abnormality in the NKCC 2 protein impairs sodium, potassium, and chloride reabsorption from the lumen. A mutated ROMK protein can also cause Bartter syndrome by impairing potassium recycling for the NKCC transporter. Bartter syndrome can also be caused by a mutated CIC-Kb, Barttin ( ), or both CIC-Ka and CIC-Ka. A mutated calcium sensing receptor (CSA) that is constitutively on can cause Bartter syndrome by down-regulating the NKCC2 in association with hypocalcemia. Impaired luminal calcium absorption causes decreased paracellular calcium absorption and hypercalciuria. Familial hypomagnesemia, hypercalciuria with nephrocalcinosis syndrome is caused by either a mutated claudin 16 or 19 protein that impairs paracellular calcium and magnesium absorption.

Table 5. Ascending limb genetic disorders.

\begin{tabular}{|c|c|c|c|c|}
\hline Gene & Protein & Inheritance & Onset & Comments \\
\hline \hline$S L C 12 A 2$ & NKCC2 & AR & Infancy & Bartter syndrome type 1 - hypokalemia, metabolic alkalosis, hypercalciuria, FTT \\
\hline$K C N J 1$ & ROMK & AR & Infancy & Bartter syndrome type 2 \\
\hline$C L C N K B$ & CLCNKB & AR & Infancy & Bartter syndrome type 3 \\
\hline$B S N D$ & Bartin & AR & Infancy & Bartter syndrome type 4, deafness \\
\hline$C A S R$ & Calcium-sensing receptor & $\mathrm{AD}$ & Childhood to adulthood & mild hypokalemia with hypocalcemia \\
\hline$C L D N-16$ & Claudin-16 & $\mathrm{AR}$ & Childhood & FHHN - familial, hypomagnesemia, hypercalciuria, nephrocalcinosis, ESRD \\
\hline$C L D N-19$ & Caludin-19 & $\mathrm{AR}$ & Childhood & FHHN \\
\hline$U M O D$ & Uromodulin & $\mathrm{AD}$ & Adolescence & \\
\hline
\end{tabular}




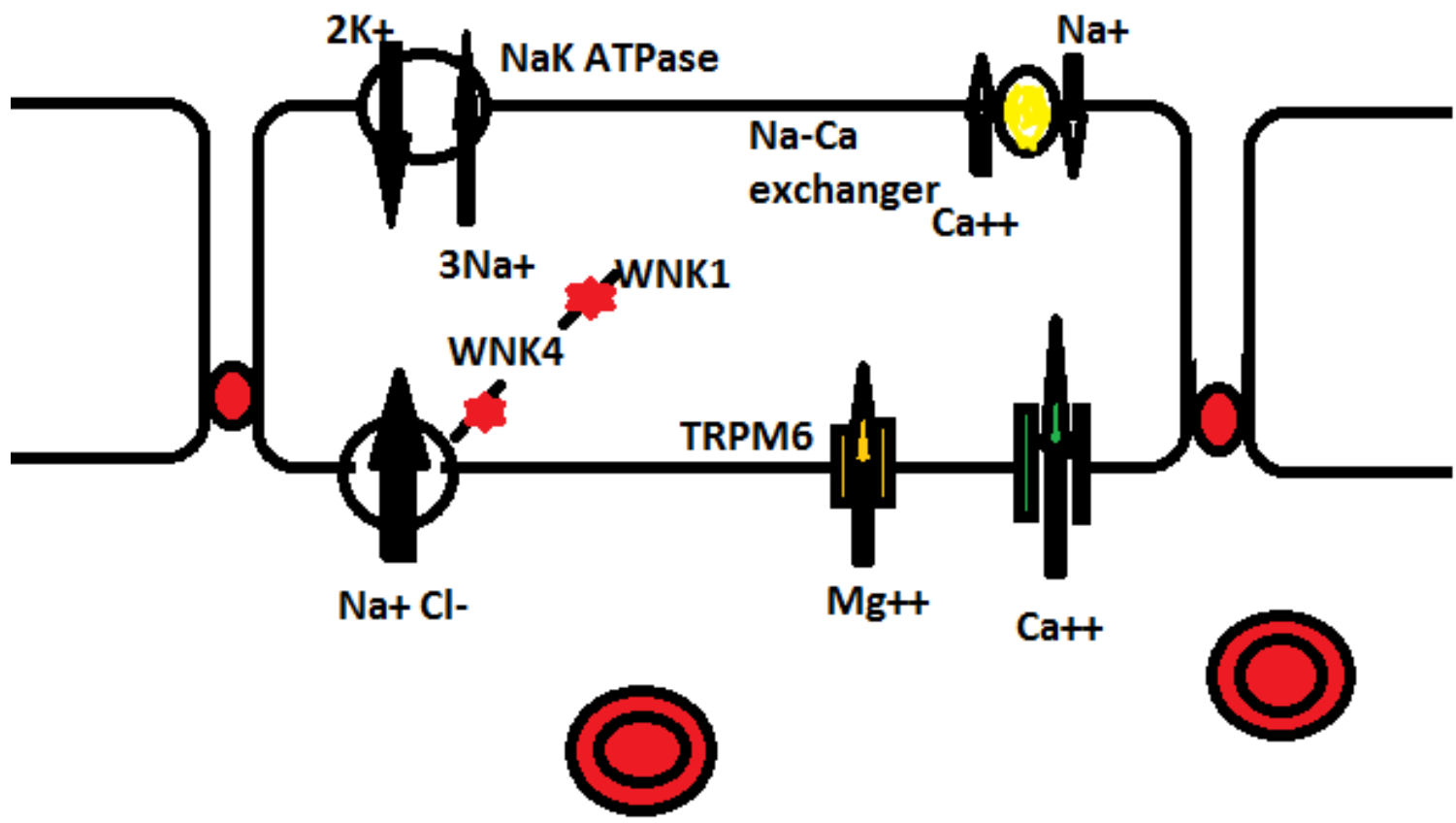

Fig. (4). Hereditary Disorders of the Distal Convoluted Tubule (DCT). Gitelman syndrome is caused by a mutated electroneutral sodiumchloride transporter. The decreased $\mathrm{NaCl}$ absorption impairs magnesium absorption through the TRPM6 channel. WNK4 inhibits the NaCl transporter and decreases $\mathrm{NaCl}$ absorption. A mutated WNK4 in Gordon syndrome leads to increased NaCl absorption in the DCT. WNK1 inhibits WNK4. A mutated WKN1 inhibits more strongly increasing $\mathrm{NaCl}$ absorption in Gordon syndrome.

Table 6. Genetic disorders of the distal convoluted tubule and collecting duct.

\begin{tabular}{|c|c|c|c|c|}
\hline Gene & Protein & Inheritance & Onset & Comments \\
\hline$S L C 12 A 3$ & NCCT & AR & Childhood to adulthood & $\begin{array}{l}\text { Gitelman syndrome - hypokalemia, } \\
\text { hypomagnesemia, tetany }\end{array}$ \\
\hline$S N N 1 B$ & B subunit of ENaC & $\mathrm{AD}$ & Childhood & $\begin{array}{l}\text { Liddle syndrome - hypertension, hypokalemia, } \\
\text { alkalosis, suppressed aldosterone and renin }\end{array}$ \\
\hline$S N N I G$ & $\Gamma$ subunit of $\mathrm{ENaC}$ & $\mathrm{AD}$ & Childhood & Liddle syndrome \\
\hline$H S D 11 B 2$ & $11 \beta$-hydroxysteroid dehydrogenase & $\mathrm{AR}$ & Childhood & $\begin{array}{l}\text { Apparent mineralocorticoid excess - } \\
\text { Hypertension, suppressed aldosterone and renin }\end{array}$ \\
\hline$W N K 1$ & WNK1 protein & AR & Childhood & $\begin{array}{l}\text { Gordon syndrome - hypertension, } \\
\text { hyperkalemia, metabolic acidosis }\end{array}$ \\
\hline WNK4 & WNK4 protein & AR & Childhood & Gordon syndrome \\
\hline$M L R$ & Mineralocorticoid receptor & $\mathrm{AD}$ & Childhood & $\begin{array}{l}\text { AD pseudohypoaldosteronism type } 1 \text { - } \\
\text { hyponatremia, hyperkalemia, salt wasting }\end{array}$ \\
\hline SNN1A & $\alpha$-subunit of $\mathrm{ENaC}$ & AR & Infancy & $\begin{array}{l}\text { AR pseudohypoaldosteronism type } 1 \text { - } \\
\text { severe salt wasting, hyperkalemia, hyponatremia }\end{array}$ \\
\hline$S N N 1 B$ & $\beta$-subunit of $\mathrm{ENaC}$ & $\mathrm{AR}$ & Infancy & AR pseudoaldosteronism \\
\hline$S N N I G$ & $\gamma$-subunit of $\mathrm{ENaC}$ & $\mathrm{AR}$ & Infancy & AR pseudoaldosteronism \\
\hline$A E 1$ & AE1 & $\mathrm{AD}$ & Infancy & dRTA \\
\hline ATP6V1B1 & $\beta$-subunit of $\mathrm{H}^{+}$-ATPase & AR & Infancy & dRTA, deafness \\
\hline ATP6V0A4 & $\alpha$-subunit of $\mathrm{H}^{+}$-ATPase & $\mathrm{AR}$ & Infancy & dRTA \\
\hline$A V P R 2$ & AVPreceptor & X-linked & Infancy & Nephrogenic diabetes insipidus \\
\hline$A Q P 2$ & Aquaporin 2 & AR & Infancy & Nephrogenic diabetes insipidus \\
\hline
\end{tabular}

childhood or even not until adulthood with tetany. They also have hypocalciuria in contrast to Bartter syndrome patients.
The hypomagnesemia is due to down-regulation of the epithelial TRPM6 channel in the distal convoluted tubule. 


\section{CORTICAL COLLECTING DUCT (FIG. 5, TABLE} 6)

\subsection{Hypertension}

Liddle syndrome is an autosomal dominant causing hypertension with variable degrees of hypokalemia and metabolic alkalosis [59]. It is caused by a mutation in either $S C N N 1 B$ or SCNN1G gene which codes for the $\beta$ or $\gamma$ subunit of the epithelial sodium channel [ENaC] [60]. ENaC mediates sodium reabsorption in the cortical collecting duct. The mutated protein is resistant to degradation and the channel remains open, longer than normal in the luminal leading to excessive sodium reabsorption, volume expansion, and hypertension. The excessive sodium reabsorption increases luminal negativity and increased potassium and hydrogen excretion. The volume expansion causes renin and aldosterone suppression which distinguishes Liddle syndrome from hyperaldoteronism.

Apparent mineralocorticoid excess [AME] is an autosomal recessive disorder that has signs and symptoms similar to Liddle syndrome [61]. It is cause by a mutation in the HSD11B2 gene that codes for the enzyme $11 \beta$ hydroxysteroid dehydrogenase [62,63]. 11 $\beta$-Hydroxysteroid dehydrogenase mediates the intracellular inactivation of cortisol preventing it from activating the mineralocorticoid receptor and increasing sodium reabsorption and hydrogen and potassium excretion. Like Liddle syndrome, AME is associated with low levels of renin and aldosterone.

Gordon syndrome or pseudohypoaldosteronism type II is another genetic cause of hypertension [64,65]. It is the clinical inverse of Gitelman syndrome with hypertension, hyperkalemia, and metabolic acidosis and is caused by a mutation in either the WNK4 or WNK1 gene which code for the WNK4 protein and WNK1 protein. In the distal convoluted tubule, WNK4 down-regulates NCCT and a mutated WNK4 leads to increased NaCL absorption. In the cortical collecting duct, WNK4 down-regulates the ROMK potassium excretory channel and the mutated protein inhibits more strongly. WNK1 inhibits WNK4 and mutations, the WNK1 gene causes increased expression and enzyme activity.

\subsection{Normotension to Hypotension}

Autosomal dominant pseudohypoaldosteronism type I [PHA1] is a rare disorder caused by a mutation in the gene $M L R$ - which codes for the intracellular mineralocorticoid receptor [66]. The mutated receptor is unable to react with aldosterone, leading to defective sodium reabsorption and potassium and hydrogen excretion. Salt wasting in autosomal dominant PHA1 tends to be mild and diminishes with age.

Autosomal recessive inheritance PHA 1 is cause by a mutation in either the $S C N N 1 A, S C N N 1 B$ or $S C N N 1 G$ genes which code for the $\alpha, \beta$, and $\gamma$ subunits of $\mathrm{ENaC}$ [67]. Infants with this disorder present with severe sodium wasting, hyperkalemia, and metabolic acidosis. They also may have transient tachypnea of the newborn and recurrent respiratory infections.

\subsection{Genetic Distal Renal Tubular Acidosis [dRTA]}

Autosomal dominant dRTA is caused by a mutation in the gene - $A E 1$ - that codes for the basolateral anion exchanger in the collecting duct intercalated cell $[68,69]$. Defective anion exchanger function inhibits bicarbonate

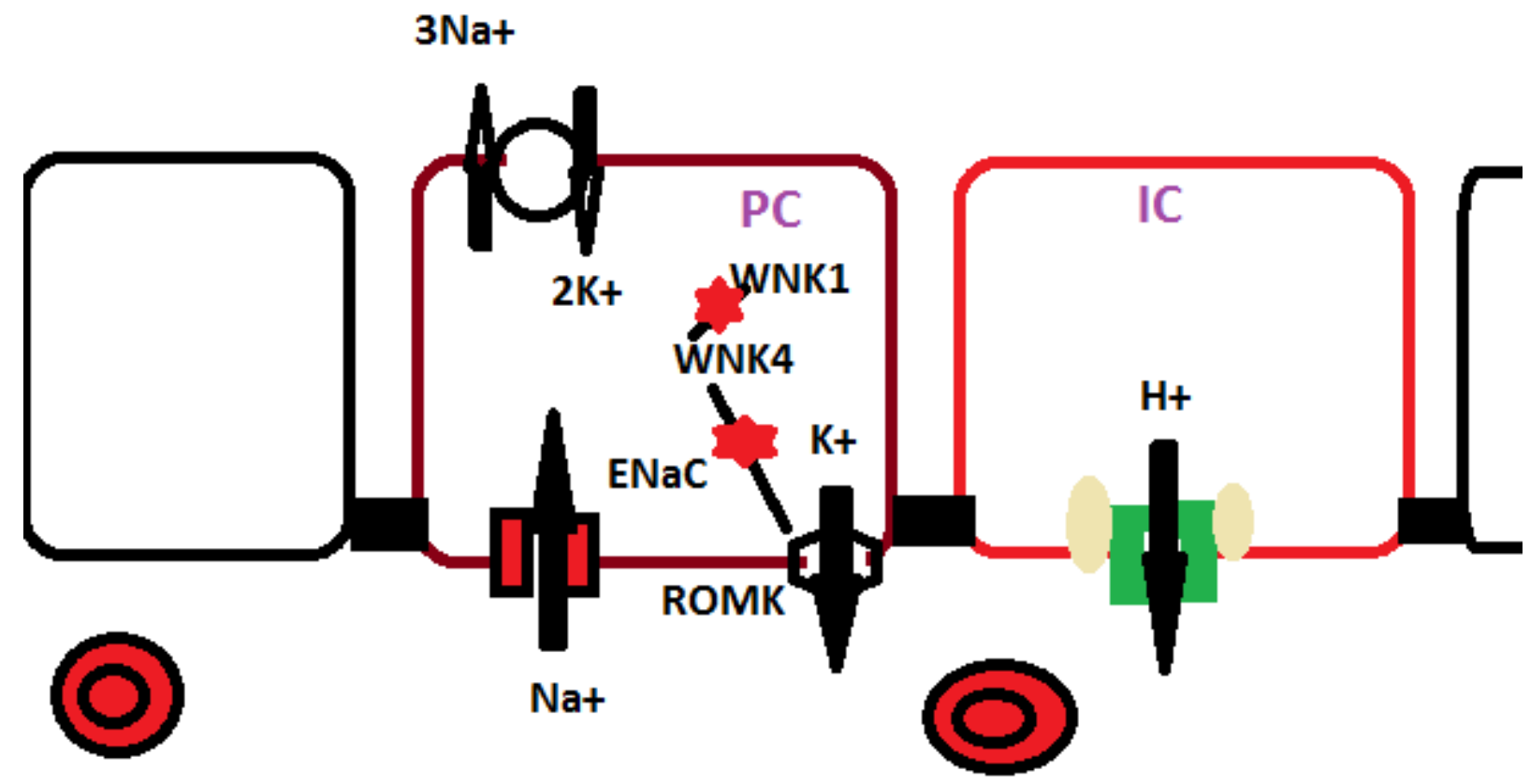

Fig. (5). Hereditary Disorders of the Collecting Duct. Sodium enter the principal cell via the epithelial sodium channel (ENaC) which is composed of the $\alpha$. B, and $\gamma$ subunits. In Liddle syndrome mutated $\beta$ or $\gamma$ subunit keeps the channel open longer and increases sodium absorption. In pseudohypoaldosteronism, a mutated $\alpha, \beta$, or $\gamma$ subunit impairs the function of the ENaC. WNK4 protein inhibits ( ) potassium secretion via the ROMK transporter. In Gordon syndrome, a mutated WNK4 protein more strongly inhibits ROMK activity. In the intercalated cell (IC) distal RTA is caused by either a mutated anion exchanger (AE1) or either the ATP6V1B1 ( ) or the ATP6V0A4 ( ) subunit of the $\mathrm{H}^{+}$-ATPase. 
transport out the cell causing cellular alkalinization and inhibition of apical hydrogen ion secretion. Affected individuals with dRTA have metabolic acidosis, hypokalemia, hypocitraturia, nephrolithiasis and nephrocalcinosis.

Autosomal recessive RTA is cause by a mutation in either the gene ATP $6 V 1 B 1$ [70], encoding the B-subunit of the apical $\mathrm{H}[+]$ ATPase or the gene ATP6VOA4 [71], encoding the a-subunit of this protein. Affected individuals with either mutation have the problems associated with dRTA and patients with a mutation in ATP6V1B1 have progressive deafness [72].

\subsection{Nephrogenic Diabetes Insipidus [NDI]}

Most patients with NDI have a mutation in the gene AVPR2 on the X chromosome [73]. AVPR2 codes for the arginine vasopressin receptor that responds to circulating vasopressin. Activation of this receptor leads to the insertion of aquaporin 2 into the luminal membrane facilitating water transport from lumen of the collecting duct. Autosomal recessive NDI is caused by mutations in the gene $A Q P 2$ which codes for aquaporin 2 [74].

\section{GENETIC CYSTIC KIDNEY DISEASE (TABLE 7)}

\subsection{Polycystic Kidney Disease}

There are a number of renal diseases, both genetic and congenital, that are associated with multiple cysts one or both kidneys. However, the term, polycystic kidney disease, is reserved for two specific hereditary kidney diseases, autosomal dominant [ADPKD] and autosomal recessive polycystic kidney disease [ARPKD]. The most common form of polycystic kidney disease manifesting in children is ARPKD $[75,76]$.

ADPKD typically presents in adults, but can be seen in children and rarely even in neonates [77,78]. It occurs in 1 out of 400-2000 live births, although it is estimated that only half of affected patients will be diagnosed as many patients have clinically silent disease. Approximately $86 \%$ of affected families have an abnormality in the PKDI gene which codes for polycystin1 [79]. Most of the remaining families have a mutation in PKD2 gene which codes for polycystin 2 [80]. While it is typically clinically silent in children, $60 \%$ of children with a known mutation have ultrasonically detectable cysts. Affected individuals usually have an increasing size and numbers of cysts over years, leading to massive nephromegaly and renal failure. Hepatic cysts are also common, especially in women.

ARPKD, previously called infantile polycystic kidney disease, typically presents in infancy, although there are childhood and adolescent forms which are generally less severe. It is caused by a mutation in the PHKD1 gene which codes for fibrocystin [81]. The cyst are small to microscopic and due to collecting duct ectasia. The estimated incidence is $1: 10,000$ to $1: 40,000$ children. ARPKD is always associated with some degree of hepatic fibrosis. About a third of affected infants will present in the neonatal period, another third of patient with ARPKD will present after infancy, and another third may not present until after the age of 20 years.

Table 7. Cystic kidney disease.

\begin{tabular}{|c|c|c|c|c|}
\hline Gene & Protein & Inheritance & Onset & Comments \\
\hline$P K D 1$ & Polycystin 1 & $\mathrm{AD}$ & Childhood to adulthood & Large renal cysts, liver cysts \\
\hline$P K D 2$ & Poycystin 2 & $\mathrm{AD}$ & Childhood to adulthood & Large renal cyst, liver cysts \\
\hline PKHD & Fibrocystin & AR & Infancy to childhood & $\begin{array}{l}\text { Nephromegaly with microcysts, } \\
\text { hepatic fibrosis, ESRD }\end{array}$ \\
\hline NPHP1 & Nephrocystin-1 & AR & Childhood & $\begin{array}{l}\text { Nephronophthisis(NPHP) type } 1 \text { - } \\
\text { interstitial fibrosis with microcysts }\end{array}$ \\
\hline Inversin & Inversin & $\mathrm{AR}$ & Infancy to childhood & $\begin{array}{l}\text { NPHP type } 2 \text {-early onset, } \\
\text { situs in versus }\end{array}$ \\
\hline NPHP3 & NPHP3 & AR & Adolescence & NPHP type 3 \\
\hline NPHP4 & Nephroretinin & $\mathrm{AR}$ & Adolescence & NPHP type 4 \\
\hline NPHP5/IQCBI & NPHP5/IQ motif containing B1 & $\mathrm{AR}$ & Childhood & NPHP type 5 \\
\hline NPHP6/CEP2901 & NPHP6/centrosome protein Cep290 & AR & Childhood & NPHP6 \\
\hline NPHP7/GLIS2 & GLIS family zinc finger protein 2 & $\mathrm{AR}$ & Adolescence & NPHP7 \\
\hline NPHP8/RPGRIPIL & RPGRIP1L & $\mathrm{AR}$ & Childhood & $\begin{array}{l}\text { NPHP8, Meckel syndrome, } \\
\text { Joubert syndrome }\end{array}$ \\
\hline NPH9/NEK8 & NIMA-related kinase & $\mathrm{AR}$ & Childhood & NPHP9 \\
\hline$S D C C A G 8$ & SDCCAG8 & AR & Childhood & NPHP10, Senior-Loken syndrome \\
\hline TMEM67 & Transmembrane protein 67 & AR & Childhood & NPHP11, hepatic fibrosis \\
\hline$T T C 21 B$ & $\begin{array}{l}\text { Tetratricopeptide repeat domain-containing } \\
\text { protein } 21 \mathrm{~B}\end{array}$ & AR & Childhood & NPHP12 \\
\hline WDR19 & WD repeat-containing protein 19 & AR & Childhood & NPHP13 \\
\hline
\end{tabular}




\subsection{Nephronophthisis}

Nephronophthisis is a group of rare autosomal recessive disorders characterized by progressive renal failure associated with tubulo-interstitial fibrosis [82-95] and is considered a "ciliopathies". It is estimated that nephronophthisis accounts for about 2-10\% of end-stage renal failure in children. The symptoms of nephronophthisis are non-specific and include: polyuria/polydipsia and recurrent dehydration. Mutations in at least 13 different genes have been associated with nephronophthisis and listed in table. Depending on the gene mutation, nephronophthisis may be associated with eye, liver and neurological disorders. The proteins from the genes associated with nephronophthisis localize to primary cilia, centrosomes, and/or adherens junctions of renal tubular cells and play an important role in cell-cell and cell-matrix signaling.

\section{CONCLUSION}

It is increasingly clear that many renal disorders in pediatrics are a consequence of genetic mutations. In the future, genetic testing will become as easy and as common as ordering a serum creatinine is today.

\section{ABBREVIATIONS}

$$
\begin{aligned}
& \text { ADPKD }=\text { Autosomal dominant polycystic kidney disease } \\
& \text { ARPKD }=\text { Autosomal recessive polycystic kidney disease } \\
& \text { AME }=\text { Apparent mineralocorticoid excess } \\
& \text { ESRD }=\text { End-stage renal disease } \\
& \text { FSGS }=\text { Focal segmental glomerulosclerosis } \\
& \text { NDI }=\text { Nephrogenic diabetes insipidus } \\
& \text { RTA }=\text { Renal tubular acidosis }
\end{aligned}
$$

\section{CONFLICT OF INTEREST}

The author confirms that this article content has no conflict of interest.

\section{ACKNOWLEDGEMENTS}

Declared none.

\section{REFERENCES}

[1] Papez KE, Smoyer WE. Recent advances in congenital nephrotic syndrome. Curr Opin Pediatr 2004; 16: 165-70.

[2] Kestila M, Lenkkeri U, Manniko M, et al. Positionally cloned gene for a novel glomerular protein - nephrin - is mutated in congenital nephrotic syndrome. Mol Cell 1998; 1: 575-82.

[3] Boute N, Gribouval O, Roselli S, et al. NPHS2, encoding the glomerular protein podocin, is mutated in autosomal recessive steroid-resistant nephrotic syndrome. Nat Genet 2000; 24: 349-54

[4] Hinkes B, Wiggins R, Gbadegesin R, et al. Positional cloning uncovers mutations in PLCE1 responsible for a nephrotic syndrome variant that may be reversible. Nat Genet 2006; 38: 1397-405.

[5] Pelletier J, Bruening W, Kashtan CE, et al. Germline mutations in the Wilms tumor suppressor gene are associated with abnormal urogenital development in Denys-Drash syndrome. Cell 1991; 67: 437-47.

[6] Colin E, Cong EH, Mollet G, et al. Loss-of-function mutations in WDR 73 are responsible for microcephaly and steroid-resistant nephrotic syndrome: Galloway-Mowat syndrome. Am J Hum Genet 2014; 95: 637-48.

[7] Buscher AK, Kranz B, Buscher A, et al. Immunosuppression and renal outcome in congenital and pediatric steroid-resistant nephrotic syndrome. Clin J Am Soc Nephrol 2010; 5: 2075-84.

[8] Niaudet P. Podosin and nephrotic syndrome: implications for the clinician. J Am Soc Nephrol 2004; 15: 832-4.

[9] Hildebrandt F, Heerings SF. Specific podocyte mutations determine the age of onset of nephrotic syndrome all the way into adult life. Kidney Int 2009; 75: 669-71.

[10] Ozaltin F, Ibsirlioglu T, Taskiran EZ, et al. Disruption of PTPRO causes childhood-onset nephrotic syndrome. Am J Hum Genet 2011; 89: 139-47.

[11] Moorthy AV, Chesney RW, Lubinsky M. Chronic renal failure and $\mathrm{XY}$ gonadal dysgenesis: "Frasier" syndrome - a commentary on reported cases. Am J Med Genet Suppl 1987; 3: 297-302.

[12] Pritchard-Jones K, Fleming S, Davidson D, et al. The candidate Wilms' tumor gene is involved in genitourinary development. Nature 1990; 346:194-7.

[13] Kaplan JM, Kim SH, North KN, et al. Mutations in ACTN4, encoding alpha-actinin-4, cause familial focal segmental glomerulosclerosis. Nat Genet 2000; 24: 251-6.

[14] Winn MP, Conlon PJ, Lynn KL, et al. A mutation in the TRPC6 cation channel causes familial focal segmental glomerulosclerosis. Science 2005; 308: 1801-4.

[15] Brown EJ, Schlondorff JS, Becker DJ, et al. Mutations in the formin gene $I N F 2$ cause focal segmental glomerulosclerosis. Nat Genet 2010; 42: 72-6.

[16] Akilesh S, Suleiman H, Yu H, et al. Arhgap24 inactvates Rac1 in mouse podocytes, and mutant form is associated with familial focal segmental glomerluosclerosis. J Clin Invest 2011;121: 4127-37.

[17] Kastan CE. Familial hematuria due to type IV collagen mutations:Alport syndrome and thin basement membrane nephropathy. Curr Opin Pediatr 2004; 16: 177-81.

[18] Torra R, Tazon-Vega B, Ars E, et al. Collagen type (\{alpha\}3\{alpha\}4) nephropathy: from isolated haematuria to renal failure. Nephrol Dial Tranpslant 2004; 19: 2429-32.

[19] Rana, K, Wang, YY, Powell, H, et al. Persistent familial hematuria in children and the locus for thin basement membrane nephropathy. Pediatr Nephrol 2005; 20: 1729-37.

[20] Dreyer SD, Zhou G, Baldini A, et al. Mutations in LMX1B cause abnormal skeletal patterning and renal dysplasia in nail-patella syndrome. Nat Genet 1998; 19: 47-50.

[21] Dreyer SD, Morello R, German MS, et al. LMX1B transactivation and expression in nail- patella syndrome. Hum Mol Genet 2000; 9: 1067-74.

[22] Zenker M, Aigner $\mathrm{T}$, Wendler $\mathrm{O}$, et al. Human laminin beta-2 deficiency causes congenital nephrosis with mesangial sclerosis and distinct eye abnormalities. Hum Mol Genet 2004; 13: 2625-32.

[23] Has C, Sparta G, Kriritsi D, et al. Integren $\alpha_{3}$ mutations with kidney, lung and skin disease. N Engl J Med 2012; 366: 1508-14.

[24] Saito T, Matsunaga A, Oikawa S, et al. Impact of lipoprotein glomerulonephropathy on the relationship between lipids and renal disease. Am J Kidney Dis 2006; 47: 199-211.

[25] Calabresi L, Pisciotta L, Costantin A, et al. The molecular basis of lecithin: cholesterol acyltransferase deficiency syndromes: a comprehensive study of molecular and biochemical findings in 13 unrelated Italian families. Arterioscler Thromb Vasc Biol 2005; 25: 1972-8.

[26] Heeringa SF, Chernin G, Chaki M, et al. COQ6 in human patienst produce nephrotic syndrome with sensorineural deafness. J Clin Invest 2011; 121: 2013-24.

[27] Lee TJ, Han HJ. Regulatory mechanisms of $\mathrm{Na}^{+} /$glucose cotransporters in renal proximal tubule cells. Kidney Int 2007; 72: S27-35.

[28] Calado SM, Loeffler J, Skallioglu O, et al. Familial renal glucosuria: SLC5A2 mutationa analysis and evidence of salt wasting. Kidney Int 2006; 69: 852-5.

[29] Camargo SM, Bockenhauer D, Kleta R. Aminoaciduria: clinical and molecular aspects. Kidney Int 2008; 73: 918-25.

[30] Strologo LD, Pras E, Pontescilli C, et al. Comparison between SLC3A1 and SCL7A9 cystinuria patients and carriers: A need for a new classification. J Am Soc Nephrol 2002; 6: 424-34.

[31] Bergwitz C, Roslin NM, Juppner H. SLC34A3 mutations in patients with hereditary hypophosphatemic rickets with hypercalciuria predict a key role for the sdium-phosphate 
cotransporter $\mathrm{NaP}_{\mathrm{i}}$-IIc in maintaining phosphate homeostasis. Am J Hum Genet 2006; 78: 179-92.

[32] Brae LA, White KE, Econs MJ. Renal phosphate wasting disorders: clinical features and pathogenesis. Semin Nephrol 2004; 24: 39-47.

[33] Sly WS, Whyte MP, Sundaram V, et al. Carbonic anhydrase type II deficiency in 12 families with the autosomal recessice syndrome of ostepetrosis with renal tubular acidosis and cerebral calcifications. N Engl J Med 1985; 313: 139-45.

[34] Igarashi T, Inatomi J, Sekine T, et al. Mutations in SLC4A4 cause permanent isolated proximal renal tubular acidosis with ocular abnormalities. Nat Genet 1999; 23: 264-6.

[35] Foreman JW. Fanconi syndrome and other proximal tubule disorders. In: Johnson RJ, Feehaly J, Floege J, Eds. Comprehensive Clinical Nephrology, $5^{\text {th }}$ ed. Phila: Elsevier Saunders 2015: pp. 590-600.

[36] Shurman SJ, Scheinman SJ. Inherited cerebrorenal syndromes. Nat Rev Nephrol 2009; 5: 529-38.

[37] Bochenhauer D, Bokencamp A, van't Hoff W, et al. Renal phenotype in Lowe syndrome: a selective proximal tubular dysfunction. Clin J Am Soc Nephrol 2008; 3: 1430-6.

[38] Cho HY, Lee NH, Choi HJ, et al. Renal manifestations of Dent disease and Lowe syndromes. Pediatr Nephrol 2008; 23: 243-9.

[39] Town M, Jean G, Cherqui S, et al. A novel gene encoding an integral membrane protein is mutated in cystinosis. Nat Genet 1998; 18: 319-24.

[40] Kleta R, Gahl WA. Pharmacological treatment of nephropathic cystinosis with cysteamine. Expert Opin Pharmacother 2004; 5: 2255-62.

[41] Gahl WA, Balog JZ, Kleta R. Nephropathic cystinosis in adults: Natural history and effect of oral cysteamine therapy. Ann Intern Med 2007; 147: 241-50.

[42] Lourdel S, Grand T, Burgos J, et al. CIC-5 mutations associated with Dent's disease: a major role of the dimer interface. Pflugers Arch 2012; 463: 247-56.

[43] Hoopes RR, Shrimpton AE, Knohl SJ, et al. Dent disease with mutations in OCRL1. Am J Hum Genet 2005; 76: 260-7.

[44] Lin T, Orrison BM, Leahey AM, et al. Spectrum of mutations in the OCRL 1 gene in Lowe oculocerebrorenal syndrome. Am J Hum Genet 1997; 60: 1384-8.

[45] Sperling O. Hereditary renal hypouricemia. Mol Genet Metab 2006; 89: 14-8.

[46] Proesmans W. Threading through the mizmaze of Bartter syndrome. Pediatr Nephrol 2006; 21: 896-902.

[47] Simon DB Karet FE, Hamblan JM, et al. Bartter syndrome, hypokalemic metabolic alkalosis with hypercalciuria, is caused by a mutation in the $\mathrm{Na}^{+} \mathrm{K}^{+} 2 \mathrm{Cl}^{-}$co-transporter $\mathrm{NKCC} 2$. Nat Genet 1996; 13: 183-8.

[48] International Collaborative Study Group for Bartter-like Syndromes. Mutations in the gene encoding for the inwardlyrectifying potassium channel, ROMK, cause the antenatal variant of Bartter syndrome: Evidence for genetic heterogeneity. Hum Mol Genet 1997; 6: 17-26.

[49] Zelikovic I, Szargel R, Hawash A, et al. A novel mutation in the chloride channel gene, $C l C K B$, as a cause of Gitelman and Bartter syndromes. Kidney Int 2003; 63: 24-32.

[50] Birkenhager R, Otto E, Schurmann MJ, et al. Mutations of BSND cause Bartter syndrome with sensorineural deafness and kidney failure. Nat Genet 2001; 29: 310-24.

[51] Vargas-Poussou R, Huang C, Hulin P, et al. Functional characterization of a calcium- sensing receptor mutation in severe autosomal dominant hypocalcemia with a Bartter like syndrome. J Am Soc Nephrol 2002; 13: 2259-66.

[52] Weber S, Schneider L, Peters M, et al. Novel paracellin-1 mutations in 25 families with familial hypomagnesemia with hypercalciuria. J Am Soc Nephrol 2001; 12: 1872-81.

[53] Naeem M, Hussain S, Akhtar N, et al. Mutation in the tightjunction gene claudin 19 (CLDN-19) and familial hypomagnesemia, hypercalciuria, nephrocalcinosis (FHHNC) and severe ocular disease. Am J Nephrol 2011; 3: 241-8.

[54] Wolf MT, Beck BB, Zaucke F, et al. The uromodulin C744G mutation causes MCKD2 and FJHH in children and adults and may be due to a possible founder effect. Kidney Int 2007; 71: 574-81.

[55] Bleyer AJ, Hart TC, Willingham MC, et al. Clinicopathologic findings in medullary cystic disease type 2. Pediatr Nephrol 2005; 20: $824-7$.
[56] Gitelman HJ, Graham JB, Welt LG. A new familial disorder characterized by hypokalemia and hypomagnesemia. Trans Assoc Am Physicians 1966; 79: 221-35.

[57] Shaer AJ. Inherited primary renal tubular hypokalemic alkalosis: a review of Gitelman and Bartter syndromes. Am J Med Sci 2001; 322: 316-32.

[58] Simon D, Nelson-Williams C, Bia MJ, et al. Gitelman variant of Bartter syndrome, inherited hypokalemic alkalosis, is caused by a mutation in the thiazide-sensitive $\mathrm{Na}^{+} \mathrm{Cl}^{-}$co-transporter. Nat Genet 1996; 12: 24-30.

[59] Palmer BF, Alpern RJ. Liddle's syndrome. Am J Med 1998; 104: 310-9.

[60] Rossier BC, Pradervand S, Schild L, et al. Epithelial sodium channel and the control of sodium balance: interaction between genetic and environmental factors. Annu Rev Physiol 2002; 64: 877-97.

[61] White PC. Abnormalities of aldosterone synthesis and action in children. Curr Opin Pediatr 1997; 9: 424-30.

[62] Stewart PM, Krozowski ZS, Gupta A, et al. Hypertension in the syndrome of apparent mineralocorticoid excess due to mutations in 11ß-hydroxysteroid dehydrogenase type II gene. Lancet 1996; 347 : 88-91.

[63] Li A, Tedde R, Krozowski ZS, et al. Molecular basis for hypertension in the "type II variant" of apparent mineralocorticorticoid excess. Am J Hum Genet 1998; 63: 370-9.

[64] Mein CA, Caulfield MJ, Dobson RI, et al. Genetics of essential hypertension. Hum Mol Genet 2004; 13: 169-75.

[65] Wilson FH, Disse-Nicoderm S, Choate KA, et al. Human hypertension caused by mutations in WNK kinases. Science 2001; 293: 1107-11.

[66] Geller DS, Soriano JR, Boado AV, et al. Mutations in the mineralocorticoid receptor gene cause autosomal pseudoaldosteronism type I. Nat Genet 1998; 19: 279-81.

[67] Chang SS, Grunder S, Hanukoglu A, et al. Mutation in the subunits of the epithelial sodium channel cause salt wasting with hyperkalemic acidosis, pseudohypoaldosteronism type I. Nat Genet 1996; 12: 248-53.

[68] Bruce LJ, Cope DL, Jones GK, et al. Familial distal renal tubular acidosis is associated with mutations in the red cell anion exchanger (Band 3) AE1 gene. J Clin Invest 1997; 100: 1693-707.

[69] Karat FE, Gainza FJ, Gyory AZ, et al. Mutations in the chloridebicarbonate exchanger gene AE1 cause autosomal dominant but not recessive distal tubular acidosis. Proc Natl Acad Sci USA 1997; 95 : $6337-42$.

[70] Karat FE, Finberg KE, Nelson RD, et al. Mutations in the gene encoding B1 subunit of the $\mathrm{H}^{+}$-TPase cause renal tubular acidosis with sensorineural deafness. Nat Genet 1999; 21: 84-90.

[71] Karat FE, Finberg KE, Nayir A et al. Localization of a gene for autosomal recessive distal renal tubular acidosis with normal hearing (rdRTA2) to 7q33-34. Am Hum Genet 1999; 65: 1656-65.

[72] Laing CM, Toye AM, Capassso G, et al. Renal tubular acidosis: developments in our understanding of the molecular basis. Int J Bio 2005; 37: 1151-61.

[73] Bichet DG. Vasopressin receptor mutations in nephrogenic diabetes insipidus. Semin Nephrol 2008; 28: 245-51.

[74] Loonen AJM, Knoers NVAM, van Os CH, et al. Aquaporin 2 mutations in nephrogenic diabetes insipidus. Semin Nephrol 2008; 28: 252-65.

[75] Parfrey PS. Autosomal-recessive polycystic kidney disease. Kidney Int 2005; 67: 1638- 48 .

[76] Guay-Woodford LM, Desmond RA. Autosomal recessive polycystic kidney disease: the clinical experience in North America. Pediatrics 2003; 111: 1072-80.

[77] Sedman A, Bell P, Manco-Johnson M, et al. Autosomal dominant polycystic kidney disease in childhood. A longitudinal study. Kidney Int 1987; 31: 1000-100.

[78] Shamshirsaz A, Bekheirnia RM, Kamgar M, et al. Autosomaldominant polycystic kidney disease in infancy and childhood: progression and outcome. Kidney Int 2005; 68: 2218-24.

[79] Hughes J, Ward CJ, Peral B, et al. The polycystic kidney disease 1 (PKD1)gene encodes a novel protein with multiple cell recognition domains. Nat Genet 1995; 10: 151-60.

[80] Tsiokas L, Arnould T, Zhu C, et al. Specific association of the gene product of PKD2 with the TRPC1 channel. Proc Natl Acad Sci USA 96; 3934-9. 
[81] Bergman C, Sendereck J, Küpper S. et al. PKHD1 mutations in autosomal recessive polycystic kidney disease (ARPKD). Hum Mutat 2004; 23: 453-63.

[82] Arts HH, Knoers NVAM. Current insights into renal ciliopathies: what can genetics teach us? Pediatr Nephrol 2013; 28: 863-74.

[83] Hildebrandt F, Otto E, Rensing C, et al. A novel gene encoding an SH3 domain protein is mutated in nephronophthisis type 1. Nat Genet 1997; 17: 149-53.

[84] Otto EA, Schermer B, Obara T, et al. Mutations in INVS encoding inversin cause nephronophthisis type 2, linking renal cystic disease to the function of primary cilia and left-right axis determination. Nat Genet 2003; 34: 413-42

[85] Olbrich H, Fliegauf M, Hoefele J, et al. Mutations in a novel gene, NPHP3, cause adolescent nephronophthisis, tapeto-retinal degeneration and hepatic fibrosis. Nat Genet 2003; 34: 455-9.

[86] Davis EE, Zhang Q, Liu Q, et al. TTC21B1 contributes both causal and modifying alleles across the ciliopathy spectrum. Nat Genet 2011; 43:189-96.

[87] Barbelanne M, Song J, Ahmadzai M, et al. Pathogenic NPHP5 mutations impair protein interaction with Cep290, a prerequisite for ciliogenesis. Hum Mol Genet 2013; 22: 2482-94.

[88] Sayer JA, Otto EA, O'Toole JF, et al. The centrosomal protein nephrocystin- 6 is mutated in Joubert syndrome and activates transcription factor ATF-4. Nat Genet 2006; 38: 674-81.
[89] Attanasio M, Uhlenhaut NH, Sousa VH, et al. Loss of GLIS causes nephronophthisis in humans and mice by increased fibrosis. Nat Genet 2007; 39:1018-24.

[90] Delous M, Baala L, Salomon R, et al. The ciliary gene RPGRIP1L is mutated in cerebello- oculo-renal syndrome (Joubert syndrome type B) and Meckel syndrome. Nat Genet 2007; 39: 875-81.

[91] Otto EA, Trapp M, Shultheiss UT, et al. NEK8 mutations affect ciliary and centrosomal localization and may cause nephronophthisis. J Am Soc Nephrol 2008; 19: 587-92.

[92] Otto EA, Hurd T, Airik R, et al. Candidate exome capture identifies mutation of SDCCAG8 as the cause of a retinal-renal ciliopathy. Nat Genet 2010; 42: 840-50.

[93] Otto EA, Tory K, Attanasio M, et al. Hypomorphic mutations in mecklin (MKS3/TMEM67) cause nephronophthisis with liver fibrosis (NPHP11). Med Genet 2009; 46: 663-70.

[94] Davis EE, Zhang Q, Liu Q, et al. TTC21B contributes both causal and modifying alleles across the ciliopathy spectrum. Nat Genet 2011; 43:189-96.

[95] Halbritter J, Porath JD, Diaz KA, et al. The GPN Study Group. The identification of 99 novel mutations in 1,056 patients with nephronophthisis-related ciliopathy. Hum Genet 2013; 132: 86584 .

(C) John Foreman; Licensee Bentham Open.

This is an open access article licensed under the terms of the Creative Commons Attribution Non-Commercial License (http://creativecommons.org/licenses/by-nc/4.0/) which permits unrestricted, non-commercial use, distribution and reproduction in any medium, provided the work is properly cited. 